\title{
Evaluation of early metabolic responses in rectal cancer during combined radiochemotherapy or radiotherapy alone: Sequential FDG-PET-CT findings
}

Citation for published version (APA):

Janssen, M. H. M., Ollers, M. C., van Stiphout, R. G. P. M., Buijsen, J., van den Bogaard, J., de Ruysscher, D., Lambin, P., \& Lammering, G. (2010). Evaluation of early metabolic responses in rectal cancer during combined radiochemotherapy or radiotherapy alone: Sequential FDG-PET-CT findings. Radiotherapy and Oncology, 94(2), 151-155. https://doi.org/10.1016/j.radonc.2009.12.033

Document status and date:

Published: 01/02/2010

DOI:

10.1016/j.radonc.2009.12.033

Document Version:

Publisher's PDF, also known as Version of record

\section{Document license:}

Taverne

Please check the document version of this publication:

- A submitted manuscript is the version of the article upon submission and before peer-review. There can be important differences between the submitted version and the official published version of record.

People interested in the research are advised to contact the author for the final version of the publication, or visit the DOI to the publisher's website.

- The final author version and the galley proof are versions of the publication after peer review.

- The final published version features the final layout of the paper including the volume, issue and page numbers.

Link to publication

\footnotetext{
General rights rights.

- You may freely distribute the URL identifying the publication in the public portal. please follow below link for the End User Agreement:

www.umlib.nl/taverne-license

Take down policy

If you believe that this document breaches copyright please contact us at:

repository@maastrichtuniversity.nl

providing details and we will investigate your claim.
}

Copyright and moral rights for the publications made accessible in the public portal are retained by the authors and/or other copyright owners and it is a condition of accessing publications that users recognise and abide by the legal requirements associated with these

- Users may download and print one copy of any publication from the public portal for the purpose of private study or research.

- You may not further distribute the material or use it for any profit-making activity or commercial gain

If the publication is distributed under the terms of Article $25 \mathrm{fa}$ of the Dutch Copyright Act, indicated by the "Taverne" license above, 
Metabolic imaging

\title{
Evaluation of early metabolic responses in rectal cancer during combined radiochemotherapy or radiotherapy alone: Sequential FDG-PET-CT findings
}

\author{
Marco H.M. Janssen *, Michel C. Öllers, Ruud G.P.M. van Stiphout, Jeroen Buijsen, Jørgen van den Bogaard, \\ Dirk de Ruysscher, Philippe Lambin ${ }^{1}$, Guido Lammering ${ }^{1}$ \\ Department of Radiation Oncology (MAASTRO), University Medical Centre Maastricht, Maastricht, The Netherlands
}

\section{A R T I C L E I N F O}

\section{Article history:}

Received 15 October 2009

Received in revised form 28 December 2009

Accepted 29 December 2009

Available online 29 January 2010

\section{Keywords:}

Metabolic treatment response

Sequential FDG-PET-CT imaging

Rectal cancer

Combined radiochemotherapy

Radiotherapy alone

\begin{abstract}
A B S T R A C T
Background and purpose: The purpose of this study was to prospectively investigate metabolic changes of rectal tumors after 1 week of treatment of either radiochemotherapy $(28 \times 1.8 \mathrm{~Gy}+$ Capecitabine) (RCT) or hypofractionated radiotherapy $(5 \times 5 \mathrm{~Gy})$ alone $(\mathrm{RT})$.

Materials and methods: Fourty-six rectal cancer patients, 25 RCT- and 21 RT-patients, were included in this study. Sequential FDG-PET-CT scans were performed for each of the included patients both prior to treatment and after the first week of treatment. Consecutively, the metabolic treatment response of the tumor was evaluated.

Results: For the patients referred for pre-operative RCT, significant reductions of $\operatorname{SUV}_{\text {mean }}(p<0.001)$ and $\operatorname{SUV}_{\max }(p<0.001)$ within the tumor were found already after the first week of treatment ( 8 Gy biological equivalent dose (BED). In contrast, 1 week of treatment with RT alone did not result in significant changes in the metabolic activity of the tumor ( $p=0.767, p=0.434)$, despite the higher applied RT dose of $38.7 \mathrm{~Gy}$ BED.

Conclusions: Radiochemotherapy of rectal cancer leads to significant early changes in the metabolic activity of the tumor, which was not the case early after hypofractionated radiotherapy alone, despite the higher radiotherapy dose given. Thus, the chemotherapeutic agent Capecitabine might be responsible for the early metabolic treatment responses during radiochemotherapy in rectal cancer.
\end{abstract}

(C) 2010 Elsevier Ireland Ltd. All rights reserved. Radiotherapy and Oncology 94 (2010) 151-155
During the last years, sequential ${ }^{18} \mathrm{~F}$-fluorodeoxyglucose positron-emission-tomography (FDG PET) imaging has been increasingly studied to monitor the metabolic response of the tumor to multimodality treatment of rectal cancer [1-12]. For rectal cancer, pre-operative short-course radiotherapy (RT) was shown to result in improved local control, whereas pre-operative treatment with radiochemotherapy (RCT) was found to result in a significant downsizing and downstaging of the tumor, increasing the rate of complete surgical resection $[2-4,9,12]$. In $15-30 \%$ of the patients being pre-operatively treated with RCT, even complete tumor regression was observed $6-8$ weeks after finishing the pre-operative treatment $[3,4,12,13]$. Over the years, many studies have been published reporting metabolic treatment response determinations of rectal carcinomas using dual time PET-imaging both before and after therapy, presenting a significant reduction of FDG uptake due to pre-operative treatment with neo-adjuvant RCT [1,3$7,10,12,14,15]$. However, in contrast to response evaluations based

\footnotetext{
* Corresponding author. Address: MAASTRO Clinic, Dr. Tanslaan 12, 6201 BN Maastricht, Box 1588, The Netherlands.

E-mail address: marco.janssen@maastro.nl (M.H.M. Janssen).

1 These authors contributed equally to this work.
}

on PET-imaging before and after treatment, monitoring the tumor response early during pre-operative treatment enables responseguided modifications of the treatment protocol on the basis of early changes of FDG uptake, possibly strengthened by additional clinical or biological factors. A significant reduction of the FDG uptake within rectal carcinomas was observed already after 2 weeks of preoperative RCT, with the reduction of the FDG uptake being a good predictor of pathological treatment response $[2,8,11]$. However, not much is known about the possible cause of early changes in the metabolic activity of rectal tumors undergoing pre-operative RCT. Therefore, in order to better understand the early metabolic changes within the tumor during RCT, we thought it might be helpful to compare the metabolic response early during RCT with the metabolic response occurring after treatment with RT alone. This could lead to a better understanding of the biological basis for early changes and could help to improve the percentage of early responding tumors, thereby also possibly improving the prognosis of patients with rectal cancer. To our knowledge, very few direct comparative studies have been performed so far [9]. Thus, a prospective study was initiated to compare early metabolic treatment response in rectal cancer undergoing either concomitant RCT or RT alone. 


\section{Materials and methods}

\section{Patient characteristics}

Fourty-six patients diagnosed with rectal cancer were included in this study, from which the clinical TN staging was obtained from a pre-treatment MR-scan according to the TNM classification of malignant tumors (Edition 6) (Table 1). The included patients were treated according to the national and regional guidelines. According to these guidelines, patients with a T2N0-1 or a mid- or highrectal T3N0-1 tumor with a predicted CRM on MR $>2 \mathrm{~mm}$ were pre-operatively treated with short-course hypofractionated RT ( 5 fractions of $5 \mathrm{~Gy}$ on consecutive working days). Patients with N2 disease, with low seated T3 tumors and patients with a tumor close to or invading the mesorectal fascia (CRM $<2 \mathrm{~mm}$ ) were treated with neo-adjuvant RCT ( 28 fractions of $1.8 \mathrm{~Gy}$ daily; Capecitabine $825 \mathrm{mg} / \mathrm{m}^{2}$ BID). Twenty-five of the included patients were preoperatively treated with RCT, whereas 21 patients were pre-operatively treated with RT alone. For the patients treated with hypofractionated short-course RT, a TME was planned within 3 days after the last RT fraction, whereas for the patients pre-operatively treated with RCT, the TME was planned approximately 3 months after the first RT fraction. The Medical Ethics Committee according to the Dutch law approved the trial. All patients gave written informed consent before entering the study.

\section{PET-CT imaging and processing}

Sequential FDG-PET-CT scans, both static and dynamic, were performed for each of the included patients at two different time points. The patients treated with RCT were imaged prior to RCT and 1 week after the onset of RCT $(10.8 \mathrm{~Gy}$, which corresponds to a biological effective dose (BED) of $8.0 \mathrm{~Gy}$ ) (Fig. 1A) [16]. Patients treated with RT were imaged prior to the start of RT and at the day of the fifth RT fraction (total dose of $25 \mathrm{~Gy}$, corresponding to a BED of $38.7 \mathrm{~Gy}$ ) (Fig. 1B) [16]. All PET-CT scans were performed as earlier described [17]. Prior to each FDG injection, the patients blood glucose level (BGL) was measured using an automatic device (LifeScan One Touch Ultra, LifeScan Inc., Milpitas, USA).

All acquired PET-data were normalized for the BGL using the following equation:

$\mathrm{SUV}_{\text {normalized }}=\mathrm{SUV} \cdot \frac{[\mathrm{Glu}]}{100}$,

with [Glu] the measured BGL [mg/dl] $[18,19]$.

Also, all dynamic PET-data were corrected for tumor motion during dynamic imaging, using the Image-Fusion-toolbox of the PMOD software package (PMOD Technologies Ltd., Zurich, Switzerland).

\section{PET analysis}

For each PET-CT scan, both static and dynamic, a tumor contour was generated using automated standardized-uptake-value (SUV) thresholding with the threshold depending on the tumor-to-background signal ratio with the gluteus muscle selected as a relevant background $[20,21]$. From the static PET-data, $S_{\text {UV }}$ mean and $S_{\text {max }}$ within the tumor were calculated using dedicated software (TrueD VC50, Siemens MI, Erlangen, Germany). For the dynamic PET-CT scans, a tumor contour was obtained from the last time frame of the dynamic PET-scan using PMOD (version 2.9, PMOD Technologies Ltd., Zurich, Switzerland). From the mean and maximum time-activity-curves (TACs) within the tumor, the FDG uptake rates $(\Delta \mathrm{SUV} / \mathrm{min}$.) were calculated over the last 8 time frames of the dynamic PET-data. Subsequently, changes in the metabolic activity of the tumor, SUVs and FDG uptake rates, were quantified by calculation of the response indices (RIs), representing the percentage reduction relative to the pre-treatment measured value.

Table 1

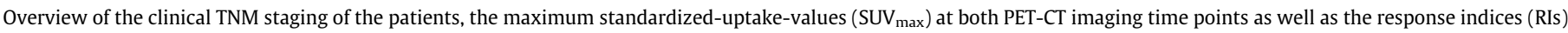
for the patients included in this study and referred to treatment with respectively radiochemotherapy (RCT) or short-course hypofractionated radiotherapy (RT).

\begin{tabular}{|c|c|c|c|c|c|c|c|c|c|}
\hline $\mathrm{RCT}$ & cTNM & $\begin{array}{l}\operatorname{SUV}_{\text {max }}[-] \\
\text { Pre }\end{array}$ & $\begin{array}{l}\operatorname{SUV}_{\text {max }}[-] \\
1 \text { week }\end{array}$ & $\begin{array}{l}\mathrm{RI} \\
\mathrm{SUV}_{\max }[\%]\end{array}$ & RT & cTNM & $\begin{array}{l}\text { SUV }_{\max }[-] \\
\text { Pre }\end{array}$ & $\begin{array}{l}\text { SUV }_{\max }[-] \\
1 \text { week }\end{array}$ & $\begin{array}{l}\text { RI } \\
\text { SUV }_{\max }[\%]\end{array}$ \\
\hline 1 & T4N2M0 & 14.4 & 10.6 & 26.4 & 1 & T3N1M1 & 18.9 & 19.3 & -2.1 \\
\hline 2 & T3N2M0 & 12.5 & 9.8 & 21.6 & 2 & T3N1M0 & 12.6 & 10.2 & 19.0 \\
\hline 3 & T3N1M0 & 20.3 & 10.9 & 46.3 & 3 & T2NOMO & 11.8 & 9.3 & 21.2 \\
\hline 4 & T2N1M0 & 17.7 & 9.0 & 49.2 & 4 & T3N1M0 & 13.0 & 13.9 & -6.9 \\
\hline 5 & T3N2M0 & 20.8 & 12.0 & 42.3 & 5 & T2NOMO & 12.2 & 14.3 & -17.2 \\
\hline 6 & T3N2M0 & 13.2 & 14.1 & -6.8 & 6 & T2NOMO & 13.4 & 11.3 & 15.7 \\
\hline 7 & T3N2M0 & 27.6 & 27.4 & 0.7 & 7 & T2N1M0 & 8.7 & 9.0 & -3.4 \\
\hline 8 & T3N1M0 & 28.1 & 16.9 & 39.9 & 8 & T3N1M0 & 22.8 & 16.8 & 26.3 \\
\hline 9 & T3N2M0 & 14.3 & 12.3 & 14.0 & 9 & T3N1M0 & 24.2 & 27.5 & -13.6 \\
\hline 10 & T3N1M0 & 16.0 & 10.6 & 33.8 & 10 & T3N1M0 & 17.6 & 15.5 & 11.9 \\
\hline 11 & T3N1M0 & 14.2 & 9.0 & 36.6 & 11 & T2NOMO & 9.4 & 10.3 & -9.6 \\
\hline 12 & T3N1M0 & 26.0 & 22.7 & 12.7 & 12 & T3N1M0 & 12.4 & 12.2 & 1.6 \\
\hline 13 & T3N2M0 & 15.2 & 14.1 & 7.2 & 13 & T2NOMO & 12.9 & 14.5 & -12.4 \\
\hline 14 & T3NOMO & 7.4 & 9.0 & -21.8 & 14 & T3N1M0 & 22.9 & 16.7 & 27.1 \\
\hline 15 & T3N2M0 & 26.2 & 19.9 & 24.0 & 15 & T3N1M0 & 12.5 & 11.0 & 12.0 \\
\hline 16 & T4N1M0 & 10.2 & 10.1 & 1.0 & 16 & T3NOMO & 14.2 & 15.2 & -7.0 \\
\hline 17 & T3N1M0 & 13.4 & 12.9 & 3.7 & 17 & T3NOMO & 16.9 & 14.6 & 13.6 \\
\hline 18 & T3N2M0 & 17.3 & 12.5 & 27.7 & 18 & T3N1M0 & 13.5 & 14.5 & -7.4 \\
\hline 19 & T3N1M0 & 19.0 & 18.9 & 0.5 & 19 & T3NOMO & 29.3 & 26.1 & 10.9 \\
\hline 20 & T3N2M0 & 11.1 & 10.0 & 9.9 & 20 & T3N1M0 & 15.7 & 18.8 & -19.7 \\
\hline 21 & T3NOMO & 11.5 & 12.7 & -10.4 & 21 & T3NOMO & 5.7 & 6.9 & -21.1 \\
\hline 22 & T4N1M0 & 15.3 & 7.6 & 50.3 & & & & & \\
\hline 23 & T3N1M0 & 7.0 & 8.0 & -14.3 & & & & & \\
\hline 24 & T3NOMO & 15.8 & 12.3 & 22.2 & & & & & \\
\hline 25 & T3N1M0 & 15.4 & 11.8 & 23.4 & & & & & \\
\hline Mean & & 16.4 & 13.0 & 17.6 & & & 15.3 & 14.7 & 1.8 \\
\hline SD & & 5.8 & 4.8 & 20.5 & & & 5.7 & 5.2 & 15.4 \\
\hline Min. & & 7.0 & 7.6 & -21.8 & & & 5.7 & 6.9 & -21.1 \\
\hline Max. & & 28.1 & 27.4 & 50.3 & & & 29.3 & 27.5 & 27.1 \\
\hline
\end{tabular}



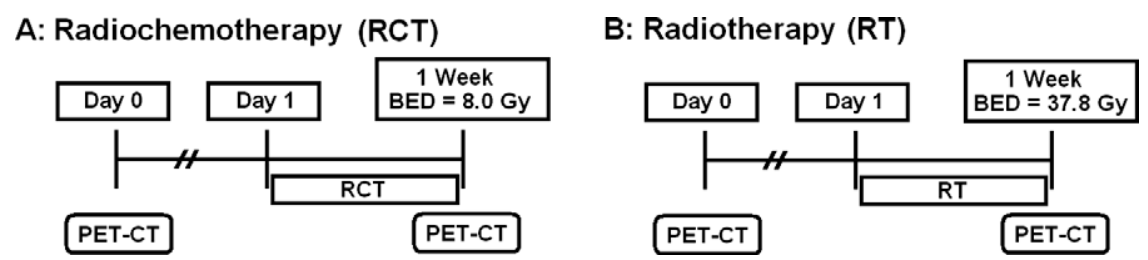

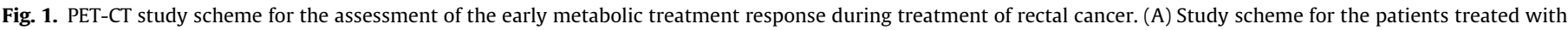
pre-operative radiochemotherapy (RCT). (B) Scheme for the patients treated with only pre-operative short-course hypofractionated radiotherapy (RT).

\section{Statistical analysis}

Statistical analyses were performed using SPSS (version 15.0; SPSS Inc., Chicago, IL, USA). All quantitative values were expressed as mean \pm standard deviation (SD) and range (min. to max.). Comparisons of related measurements were performed using a Wilcoxon-signed rank test, whereas a Mann-Whitney $U$ test was used in case of independent samples.

\section{Results}

\section{Metabolic treatment response during $R C T$}

A significant decrease of the metabolic activity within the tumor was observed already early during pre-operative RCT (Fig. 2A). $\mathrm{SUV}_{\text {mean }}$ and $\mathrm{SUV}_{\text {max }}$ decreased from respectively $8.5 \pm 2.8$ (range: 4.0-15.1) and $16.4 \pm 5.8$ (range: 7.0-28.1) measured prior to the onset of RCT to $6.9 \pm 2.2$ (range: $4.3-12.7)(p<0.001)$ and $13.0 \pm 4.8$ (range: 7.6-27.4) $(p<0.001)$ after the first week of RCT (Table 1$)$. Comparable time-trends were found for the mean and maximum FDG uptake rates within the tumor, with RIs of respectively $21.0 \pm 31.3 \%$ (range: $-40.6 \%$ to $65.2 \%)(p=0.003)$ and $11.4 \pm 41.5 \%$ (range: $-73.1 \%$ to $60.7 \%$ ) ( $p=0.062$ ) after the first week of RCT (Fig. 2A).

\section{Metabolic treatment response during $R T$}

In contrast to RCT, for the patients pre-operatively treated with RT, no significant reduction of the tumors metabolic activity $\left(\mathrm{SUV}_{\text {mean }}\right.$ and $\left.\mathrm{SUV}_{\max }\right)$ was observed early during therapy (Fig. 2B). Average values of respectively $8.3 \pm 2.9$ (range: 3.4-15.1) and $15.3 \pm 5.7$ (range: $5.7-29.3$ ) were found for the pre-treatment PETCT scan and $8.2 \pm 2.7$ (range: $4.4-14.3)(p=0.767)$ and $14.7 \pm 5.2$ (range: $6.9-27.5)(p=0.434)$ for the follow-up PET-data (Table 1$)$.
For the mean and maximum FDG uptake rate of the tumor, RIs of respectively $-9.9 \pm 30.5 \%$ (range: $-52.6 \%$ to $44.9 \%)(p=0.334$ ) and $-6.7 \pm 22.4 \%$ (range: $-41.2 \%$ to $33.0 \%)(p=0.293$ ) were found (Fig. 2B).

\section{$R C T$ versus $R T$}

When comparing the metabolic treatment response of the two different treatment schemes after 1 week of treatment, a significant higher metabolic response was found for the patients treated with RCT when compared to pre-operative treatment with RT alone (Fig. 3 and Table 1 ). The average reduction of $\mathrm{SUV}_{\text {mean }}$ of $16.4 \pm 18.2 \%$ (range: $-20.9 \%$ to $47.6 \%$ ) after the first week of RCT was found to be statistically significantly higher when compared to the average reduction of only $0.1 \pm 14.7 \%$ (range: $-29.4 \%$ to 23.5\%) for the patients treated with RT alone ( $p=0.004)$ (Fig. 3).

Also, the percent reduction of $\mathrm{SUV}_{\max }$ of $17.6 \pm 20.5 \%$ (range: $-21.8 \%$ to $50.3 \%$ ) after 1 week of RCT was found to be statistically significant higher than the average reduction of $\mathrm{SUV}_{\max }$ of $1.8 \pm 15.4 \%$ (range: $-21.1 \%$ to $27.1 \%$ ) after 1 week of RT alone $(p=0.009)$ (Fig. 3 and Table 1$)$.

\section{Discussion}

In the present report we provide first evidence that the significant reduction of the metabolic activity of the tumor, as seen early during pre-operative RCT might be induced by the chemotherapeutic agent Capecitabine, since no such changes in the metabolic activity of the tumor could be determined after 1 week of treatment with RT alone, despite the much higher applied BED. When looking at only the dose levels of RT, a higher metabolic treatment response was expected for the patients treated with hypofractionated RT at the time of the follow-up PET-CT scan as these patients
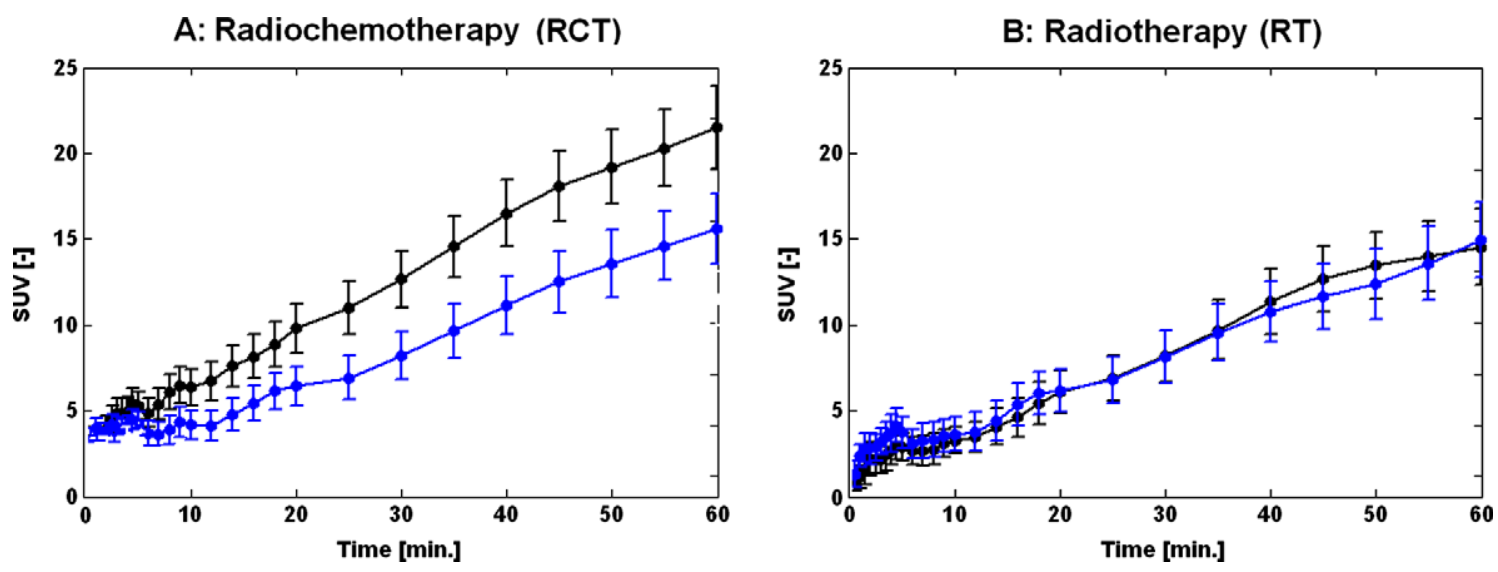

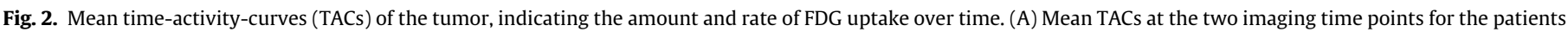

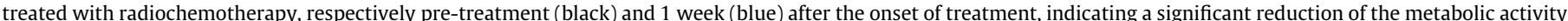

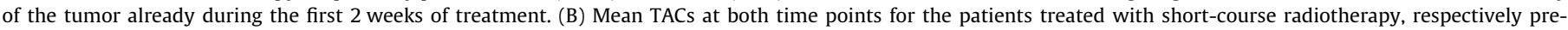
treatment (black) and after 1 week of treatment (blue), presenting a stable FDG uptake within the tumor during treatment with RT. 


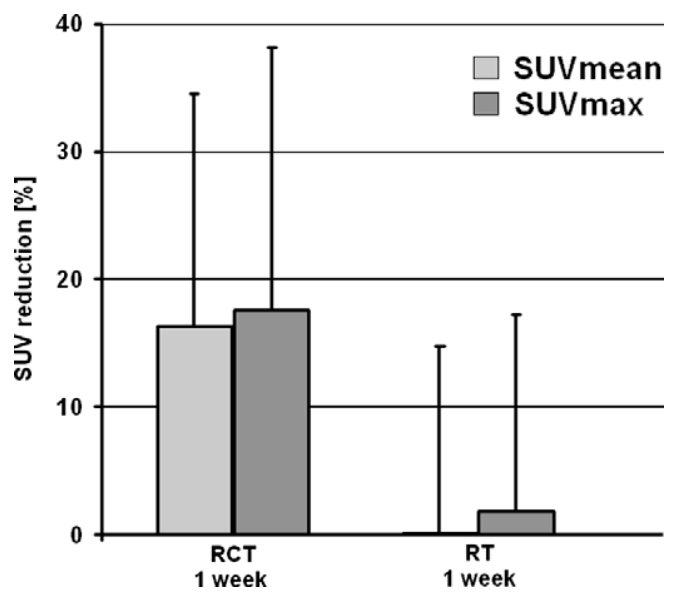

Fig. 3. Average reductions of both $S_{U V} V_{\text {mean }}$ and $S U V_{\max }$ within the tumor after 1 week of treatment for the patients treated with respectively radiochemotherapy (RCT) and short-course hypofractionated radiotherapy (RT).

received a higher BED when compared to the patients treated with RCT. However, this study presents with opposite findings. These findings imply that the addition of the chemotherapeutic agent Capecitabine to RT-treatment can induce the early metabolic decrease in the FDG uptake, which is more and more used as a predictor of the pathological treatment response.

A comparative study, investigating the metabolic activity of the tumor early during chemotherapy alone was unfortunately not feasible, because initial chemotherapy alone is not standard care in our region. However, earlier clinical studies have already indicated important and even prognostic significant differences in FDG uptake as early as one to three weeks after the first cycle of chemotherapy in various cancer types [22-26]. For chemotherapy with 5-FU, a comparable chemotherapeutic drug to Capecitabine, a consistent decrease in FDG uptake by $50 \%$ was already present as early as 3 days after the start of the chemotherapy [27]. In contrast, chemotherapeutic agents like doxorubicin or paclitaxel increased FDG uptake [27]. The early reduction in FDG uptake under 5-FU treatment might be related to a decreased activity of either the glucose transporter Glut-1 or the phosphorylation enzyme hexokinase [27]. Also for rectal cancer patients, a significant reduction of FDG uptake was observed when applying chemotherapy alone without additional RT [28-30]. Sharma and Smith presented data demonstrating a significant reduction of the hexokinase activity in colorectal tumor cells after treatment with chemotherapy [31]. Hexokinase is an enzyme known to phosphorylate six-carbon sugars, including FDG, making it unable to move or be transported out of the cell [31]. A reduction of the hexokinase concentration leads to a decreased amount of FDG trapped within the cells resulting in decreased SUVs [31]. The degree of chemotherapy-induced changes in metabolic activity of colorectal tumors were shown to be highly predictive for patient outcome [30].

Such FDG uptake measurements provide a valuable surrogate for the intratumoral biodistribution of the drug within solid tumors and thereby also for the intratumoral effectiveness. A homogeneous intratumoral biodistribution of the drug Capecitabine is an important prerequisite for its effectiveness as a radiosensitizing cancer cell agent during RT [32].

In contrast to chemotherapeutic agents, RT alone on cancer cells does not lead to early changes in its glucose transport or cellular hexokinase activity [32]. Instead, RT induces changes on the cellular cell cycle, the DNA repair and apoptosis, all of which do probably not lead to early changes in the FDG uptake of cancer cells, as seen in our study [32]. Thus, the metabolic changes in PET images after the first week of RCT in rectal cancer might be more seen as activity changes in the cells ability to incorporate glucose under the influence of the chemotherapeutic drug rather than as RT-induced cytotoxicity.

This is the first study presenting significant different reaction patterns of rectal tumors to pre-operative treatment with either radiochemotherapy or radiotherapy alone already early during treatment. Knowledge about early reaction patterns within malignancies during pre-operative treatment is important for further evaluation of PET-based response predictions which are the first elements of individualized treatment schemes in the near future.

One published study presented with contradicting results as they found a significant reduction in the FDG uptake after a short-course hypofractionated RT [9]. One of the differences between the study of Siegel et al. and our study was the later time point of 2 days of the follow-up PET-CT scan [9]. However, the average difference of only 2 days is very unlikely to explain such a dramatic reduction of more than $35 \%$ for the $S_{U V} V_{\max }$. Instead, another explanation for the discrepancy of the results might be the reproducibility of SUV determination [12,18,20,33-36]. The patients BGL at the time of PET-imaging and the time-interval between FDG injection and the start of PET-imaging are known to influence the SUVs resulting from PET analysis [12,18,33-36]. The study of Siegel et al. did not perform a normalization of the sequential PET-data for the patient's BGL at the time of the PETimaging [9]. A lack of BGL-normalization however could in cases of large intra-patient BGL fluctuations lead to misinterpretations of the SUV time-trends [12,33-36]. Also, Siegel et al. performed only static PET-acquisition approximately $60 \mathrm{~min}$ after intravenous injection of FDG. The major drawback of static PET-imaging however is the time dependency of SUV determination because of continuous FDG uptake within the tumor for several hours after FDG injection [12,33]. The use of an identical time-interval between FDG injection and the start of PET-imaging is essential when performing sequential FDG-PET-CT-scans for metabolic response evaluations [12]. To overcome this time dependency, we additionally performed dynamic PET-imaging in the majority of the study patients. By looking at the average FDG uptake rate within the tumor, before reaching a plateau, instead of only at a SUV at a single time point, the time dependency of SUV determination no longer influences the time-trends of FDG uptake during therapy. Another important confounder in the use of PET-imaging is a peritumoral inflammatory reaction, as inflammatory cells are known to avidly consume FDG $[11,37]$. An increased FDG uptake by inflammatory cells in the direct neighborhood of the tumor can lead to an underestimation of the SUV decrease within the tumor [8,11]. To ensure a reliable comparison of the metabolic treatment response of the two treatment schemes without bias due to inflammatory reactions, only patients without a visually observable peritumoral inflammatory reaction were included in this study.

As described, the patients included in this study were treated according to the national guidelines with either short-course hypofractionated radiotherapy or radiochemotherapy, based on their clinical TNM stage and predicted CRM determined from MR-imaging. So, the included patients were not enrolled in a randomized two-arm trial. However, this was not expected to result in a bias of the results of this study. The patients diagnosed with locally advanced rectal cancer presented with higher tumor volumes compared to the patients diagnosed with non-locally advanced rectal cancer. Larger tumors are more likely to have hypoxic regions, being less sensitive to radiotherapy treatment. So, a possible bias would have more likely resulted in a higher metabolic treatment response in the smaller non-locally advanced rectal tumors treated with a high BED when compared to the larger locally advanced rectal tumors treated with a relatively low BED, which is the opposite of our findings.

In conclusion, already after the first week of radiochemotherapy, the metabolic activity of the tumor was found to decrease sig- 
nificantly, which was not detectable early after treatment with radiotherapy alone, suggesting the chemotherapeutic agent Capecitabine as the primary initiator of the observed reduction of the tumors metabolic activity.

\section{Conflict of interest statement}

We are not aware of any actual or potential conflicts of interest.

\section{Acknowledgements}

The authors would like to thank Siemens MI for technical and financial support. We also acknowledge financial support from the Netherlands Organization for Health Research and Development (ZonMw; clinical fellowship awarded to G.L.).

\section{References}

[1] Kalff V, Duong C, Drummond EG, Matthews JP, Hicks RJ. Findings on 18F-FDG PET scans after neoadjuvant chemoradiation provides prognostic stratification in patients with locally advanced rectal carcinoma subsequently treated by radical surgery. J Nucl Med 2006;47:14-22.

[2] Cascini GL, Avallone A, Delrio P, et al. 18F-FDG PET is an early predictor of pathologic tumor response to preoperative radiochemotherapy in locally advanced rectal cancer. J Nucl Med 2006;47:1241-8.

[3] Capirci C, Rampin L, Erba PA, et al. Sequential FDG-PET/CT reliably predicts response of locally advanced rectal cancer to neo-adjuvant chemo-radiation therapy. Eur J Nucl Med Mol Imaging 2007;34:1583-93.

[4] Capirci C, Rubello D, Chierichetti F, et al. Long-term prognostic value of $18 \mathrm{~F}-$ FDG PET in patients with locally advanced rectal cancer previously treated with neoadjuvant radiochemotherapy. AJR Am J Roentgenol 2006;187:W202-8.

[5] Amthauer H, Denecke T, Rau B, et al. Response prediction by FDG-PET after neoadjuvant radiochemotherapy and combined regional hyperthermia of rectal cancer: correlation with endorectal ultrasound and histopathology. Eur J Nucl Med Mol Imaging 2004;31:811-9.

[6] Denecke T, Rau B, Hoffmann KT, et al. Comparison of CT, MRI and FDG-PET in response prediction of patients with locally advanced rectal cancer after multimodal preoperative therapy: is there a benefit in using functional imaging? Eur Radiol 2005; 15:1658-66.

[7] Guillem JG, Moore HG, Akhurst T, et al. Sequential preoperative fluorodeoxyglucose-positron emission tomography assessment of response to preoperative chemoradiation: a means for determining longterm outcomes of rectal cancer. J Am Coll Surg 2004;199:1-7.

[8] Rosenberg R, Herrmann K, Gertler R, et al. The predictive value of metabolic response to preoperative radiochemotherapy in locally advanced rectal cancer measured by PET/CT. Int J Colorectal Dis 2009;24:191-200.

[9] Siegel R, Dresel S, Koswig S, et al. Response to preoperative short-course radiotherapy in locally advanced rectal cancer: value of f-fluorodeoxyglucose positron emission tomography. Onkologie 2008;31:166-72.

[10] Vliegen RF, Beets-Tan RG, Vanhauten B, et al. Can an FDG-PET/CT predict tumor clearance of the mesorectal fascia after preoperative chemoradiation of locally advanced rectal cancer? Strahlenther Onkol 2008;184:457-64.

[11] Janssen MH, Ollers MC, Riedl RG, et al. Accurate prediction of pathological rectal tumor response after 2 weeks of pre-operative radiochemotherapy using FDG-PET-CT imaging. Int J Radiat Oncol Biol Phys 2009; doi:10.1016/ j.ijrobp.2009.04.030.

[12] Hindie E, Hennequin C, Moretti JL. Predicting response to chemoradiotherapy in rectal and oesophageal cancer with 18F-FDG: prognostic value and possible role in patient management. Eur J Nucl Med Mol Imaging 2007;34:1576-82.

[13] Valentini V, Coco C, Cellini N, et al. Ten years of preoperative chemoradiation for extraperitoneal $\mathrm{T} 3$ rectal cancer: acute toxicity, tumor response, and sphincter preservation in three consecutive studies. Int J Radiat Oncol Biol Phys 2001;51:371-83.

[14] Roedl JB, Colen RR, Holalkere NS, Fischman AJ, Choi NC, Blake MA Adenocarcinomas of the esophagus: response to chemoradiotherapy is associated with decrease of metabolic tumor volume as measured on PETCT. Comparison to histopathologic and clinical response evaluation. Radiother Oncol 2008;89:278-86.

[15] Petit SF, Aerts HJ, van Loon JG, et al. Metabolic control probability in tumour subvolumes or how to guide tumour dose redistribution in non-small cell lung cancer (NSCLC): an exploratory clinical study. Radiother Oncol 2009;91:393-8.

[16] Glimelius B, Gronberg H, Jarhult J, Wallgren A, Cavallin-Stahl E. A systematic overview of radiation therapy effects in rectal cancer. Acta Oncol 2003;42:476-92.

[17] Janssen MH, Aerts HJ, Ollers MC, et al. Tumor delineation based on timeactivity curve differences assessed with dynamic fluorodeoxyglucose positron emission tomography-computed tomography in rectal cancer patients. Int J Radiat Oncol Biol Phys 2009;73:456-65.

[18] Beaulieu S, Kinahan P, Tseng J, et al. SUV varies with time after injection in (18)F-FDG PET of breast cancer: characterization and method to adjust for time differences. J Nucl Med 2003;44:1044-50.

[19] Eary JF, Mankoff DA. Tumor metabolic rates in sarcoma using FDG PET. J Nucl Med 1998;39:250-4.

[20] Ollers M, Bosmans G, van Baardwijk A, et al. The integration of PET-CT scans from different hospitals into radiotherapy treatment planning. Radiother Oncol 2008;87:142-6.

[21] Daisne JF, Sibomana M, Bol A, Doumont T, Lonneux M, Gregoire V. Tridimensional automatic segmentation of PET volumes based on measured source-to-background ratios: influence of reconstruction algorithms. Radiother Oncol 2003;69:247-50.

[22] Kostakoglu L, Coleman M, Leonard JP, Kuji I, Zoe H, Goldsmith SJ. PET predicts prognosis after 1 cycle of chemotherapy in aggressive lymphoma and Hodgkin's disease. J Nucl Med 2002;43:1018-27.

[23] Juweid ME, Cheson BD. Positron-emission tomography and assessment of cancer therapy. N Engl J Med 2006;354:496-507.

[24] Ott K, Fink U, Becker K, et al. Prediction of response to preoperative chemotherapy in gastric carcinoma by metabolic imaging: results of a prospective trial. J Clin Oncol 2003;21:4604-10.

[25] Weber WA, Ott K, Becker K, et al. Prediction of response to preoperative chemotherapy in adenocarcinomas of the esophagogastric junction by metabolic imaging. J Clin Oncol 2001;19:3058-65.

[26] Weber WA, Petersen V, Schmidt B, et al. Positron emission tomography in nonsmall-cell lung cancer: prediction of response to chemotherapy by quantitative assessment of glucose use. J Clin Oncol 2003;21:2651-7.

[27] Direcks WG, Berndsen SC, Proost N, et al. [18F]FDG and [18F]FLT uptake in human breast cancer cells in relation to the effects of chemotherapy: an in vitro study. Br J Cancer 2008;99:481-7.

[28] Dimitrakopoulou-Strauss A, Strauss LG, Burger C, et al. Prognostic aspects of 18F-FDG PET kinetics in patients with metastatic colorectal carcinoma receiving FOLFOX chemotherapy. J Nucl Med 2004;45:1480-7.

[29] Dimitrakopoulou-Strauss A, Strauss LG, Rudi J. PET-FDG as predictor of therapy response in patients with colorectal carcinoma. Q J Nucl Med 2003;47:8-13.

[30] de Geus-Oei LF, van Laarhoven HW, Visser EP, et al. Chemotherapy response evaluation with FDG-PET in patients with colorectal cancer. Ann Oncol 2008; 19:348-52.

[31] Sharma RI, Smith TA. Colorectal tumor cells treated with 5-FU, oxaliplatin, irinotecan, and cetuximab exhibit changes in 18F-FDG incorporation corresponding to hexokinase activity and glucose transport. J Nucl Med 2008;49:1386-94.

[32] Schoder H, Ong SC. Fundamentals of molecular imaging: rationale and applications with relevance for radiation oncology. Semin Nucl Med 2008;38:119-28.

[33] Keyes Jr JW. SUV: standard uptake or silly useless value? J Nucl Med 1995;36:1836-9.

[34] Langen KJ, Braun U, Rota Kops E, et al. The influence of plasma glucose levels on fluorine-18-fluorodeoxyglucose uptake in bronchial carcinomas. J Nucl Med 1993;34:355-9.

[35] Lindholm P, Minn H, Leskinen-Kallio S, Bergman J, Ruotsalainen U, Joensuu H. Influence of the blood glucose concentration on FDG uptake in cancer - a PET study. J Nucl Med 1993;34:1-6.

[36] Crippa F, Gavazzi C, Bozzetti F, et al. The influence of blood glucose levels on [18F]fluorodeoxyglucose (FDG) uptake in cancer: a PET study in liver metastases from colorectal carcinomas. Tumori 1997;83:748-52.

[37] Kao PF, Chou YH, Lai CW, Diffuse FDG. Uptake in acute prostatitis. Clin Nucl Med 2008;33:308-10. 